\title{
Patient and practitioner compliance with silicone hydrogel and daily disposable lens replacement in Canada
}

\author{
BY DORIS RICHTER, MASc, OD; KATHY DUMBLETON, MSc, MCOptom, FAA0; SARAH GUTHRIE, PhD; \\ CRAIG WOODS, PhD, MCOptom, FAA0; LYNDON JONES, PhD, FCOptom, FAAO; DESMOND FONN, MOptom, FAAO
}

\section{Introduction}

Tost soft contact lenses pre1 scribed today are designed to be replaced at regular intervals, ranging from one day to one month. In a survey of worldwide contact lens prescribing patterns in $2008,{ }^{1}$ monthly-replacement lenses were most frequently prescribed for new fits of soft lenses in Canada $(75 \%)$, followed by twoweekly $(14 \%)$ and daily disposable $(11 \%)$ lenses. A number of studies have shown that frequent replacement of hydrogel contact lenses results in fewer deposits, lower incidence of complications and greater overall satisfaction, compared to lenses worn for longer periods of time. ${ }^{2-8}$ The extent to which these benefits are realized depends, in part, on compliance with lens replacement recommendations. Previous studies have shown that patients are not always compliant with replacement schedules, 9-12

\section{ABSTRACT}

Purpose: To assess current recommendations by optometrists for replacement frequency (RF) of silicone hydrogels (SH) and daily disposable (DD) contact lenses in Canada, determine rates of non-compliance with recommendations by both the optometrist and patient, and investigate reasons for non-compliance.

Methods: Survey packages were sent to optometrists in Canada who had agreed to participate. Patients completed survey questions regarding demographics and contact lens wearing patterns, including recommended and actual contact lens RF. Optometrists were asked to provide lens information and their recommendation for RF. Fifty-eight optometrists returned 654 surveys, of which 578 were eligible for analysis.

Results: Seventy percent of patients were female with a median age of 32 years. Lens type distribution was 18\% DD, 35\% two-week SH, and 47\% one-month SH. Six percent were worn for extended wear. Daily wear median wearing time was 12 hours/day, a median of five days/week for DD, seven days/week for SH (two-week and one-month). Optometrists'secommendations were non-compliant with the manufacturers' recommended RF for
$6 \%$ of DD, 35\% of two week, and $2 \%$ of one-month patients. Patients were non-compliant with recommendations from both the manufacturer and optometrist for $12 \%$ of DD, $43 \%$ of two-week, and $31 \%$ of one-month lens wearers. The most common reason for non-compliance was forgetting which day to replace lenses. Fifty-six percent thought a reminder system would help with compliance. A higher proportion of compliant patients followed the RF because of confidence in their optometrist.

Conclusions: Optometrists generally recommended RFs consistent with manufacturers' recommendations for DD and one-month SH lenses but often recommended longer intervals for two-week SH lenses. Patients were most compliant when wearing DD lenses and least compliant when wearing two-week SH lenses. Communication between the patient and optometrists concerning the risks of non-compliance, or initiating a reminder system might improve compliance.

Keywords: Silicone hydrogel, daily disposable, contact lens, replacement frequency, compliance 
but none of these have specifically looked at silicone hydrogel lenses which now account for nearly $50 \%$ of new soft lens fits in Canada. ${ }^{1,13}$

The aim of this study was to assess current recommendations by optometrists for replacement frequency (RF) of silicone hydrogels (SH) and daily disposable (DD) contact lenses in Canada. In addition, the rates of non-compliance with manufacturer recommended replacement frequency (MRRF) by optometrists and patients were determined and the reasons for noncompliance investigated.

\section{Methods}

\section{Study design}

This study followed the design utilized in a similar study that sought information from USA eye care practitioners and their DD and $\mathrm{SH}$ lens wearers. ${ }^{14}$ Invitations to participate in this voluntary study were sent by email to approximately 2,500 optometrists in Canada. The Canadian Association of Optometrists invited its members to take part in the study.

Survey packages were mailed by the Centre for Contact Lens Research (CCLR) to optometrists who volunteered to participate. The optometrists were provided with an explanatory covering letter and were instructed to ask the next 20 soft contact lens-wearing patients (either DD or two-week or one-month SH lenses) attending their practice to complete the survey. Completion of the survey was voluntary and the patients completing it retained anonymity. After completing the survey, each patient was asked to seal the survey in an envelope, on which the optometrist recorded that respondent's lens type, powers for each eye and optometrist-recommended replacement schedule on the outside. The optometrist then returned all completed surveys (in their sealed envelopes) to the CCLR in a postagepaid envelope. Optometrists were not identified on the returned surveys in order to provide some degree of anonymity from the CCLR.

Ethics clearance was obtained through the Office of Research Ethics at the University of Waterloo and the study was conducted following the tenets of the Declaration of Helsinki.

\section{The survey}

The three-page survey consisted of a series of questions regarding the patient and their contact lens history, including recommended and actual contact lens replacement frequency. Questions were also included to determine the reasons for not complying with recommended replacement intervals and to investigate instructions provided by the optometrist regarding contact lens replacement.

\section{Data analysis}

Where relevant, data analyses were conducted using Statistica 8.0 (StatSoft Inc. Tulsa, OK). Data are presented as percentages or mean \pm standard deviation. When interval estimates are included, they are $95 \%$ confidence limits of the estimate.

\section{Results}

\section{Respondents}

Fifty-eight optometrists (52\% of those optometrists who registered their interest in participation) returned 654 patient surveys $(29 \%$ of the total surveys sent out). The data from 578 patient respondents were eligible for analysis (88\% of completed surveys received). The remaining surveys either did not have sufficient information recorded for analysis, or were completed by patients wearing ineligible lens brands.

\section{Lens brands and powers}

The brands of lenses worn by patients, as recorded by their optometrists, are listed in Table 1. Eighteen percent of the lenses worn were daily disposable (DD), 35\% were two-week replacement silicone hydrogels (two-week $\mathrm{SH}$ ) and $47 \%$ were one-month replacement silicone hydrogels (one-month $\mathrm{SH}$ ).

The lens brand worn, as reported by the patients, matched that reported by the optometrist for $66 \%$ of participating patients. In 5\% of cases, the lens types did not match, and $29 \%$ of patients were unsure of the lens type they were wearing.

\section{Demographics and lens wearing patterns}

Seventy percent of the surveys analysed were completed by female patients. The mean age of all patients was $33.7 \pm 12.7$ years (range $14-77$ years) with a median patient age of 32 years. The patients surveyed were experienced contact 
lens wearers; the mean number of years wearing any type of contact lenses was $12.1 \pm 9.4$ (range 0.1 to 49 years) with a median of 10 years.

Lenses were reported to be worn $5.6 \pm 1.9$ days each week (range $1-$ 7 days) with a median of 5 days for DD lenses and 7 days for two-week and one-month SH lenses. The percentage of patients wearing lenses fewer than seven days per week was higher for DD lenses $(70 \%, 60-$ $79 \%)$ than for two-week $(39 \%, 32-$ $48 \%$ ) or one-month lenses $(39 \%, 33$ $-45 \%)$. The mean wearing time of lenses worn for daily wear was 11.9 \pm 3.4 hours each day (range $2-19$ hours) with a median of 12 hours. Overall, $6 \%$ of patients reported wearing lenses for 24 hours each day; this varied by lens group, with the rates being $3 \%(1-9 \%)$ for DD lenses, $<1 \%(0-3 \%)$ for two-week lenses and $11 \%(7-15 \%)$ for onemonth lenses.

\section{Optometrist compliance with} recommended replacement frequency

\section{Data obtained from optometrists}

The distribution of responses for the optometrist recommended replacement frequency (ORRF) for each lens group is listed in Table 2. A replacement frequency was considered compliant with the manufacturer's recommendations (MRRF) if the interval between replacements was less than or equal to the recommendation. The highlighted cells in Table 2 represent ORRFs that are compliant.

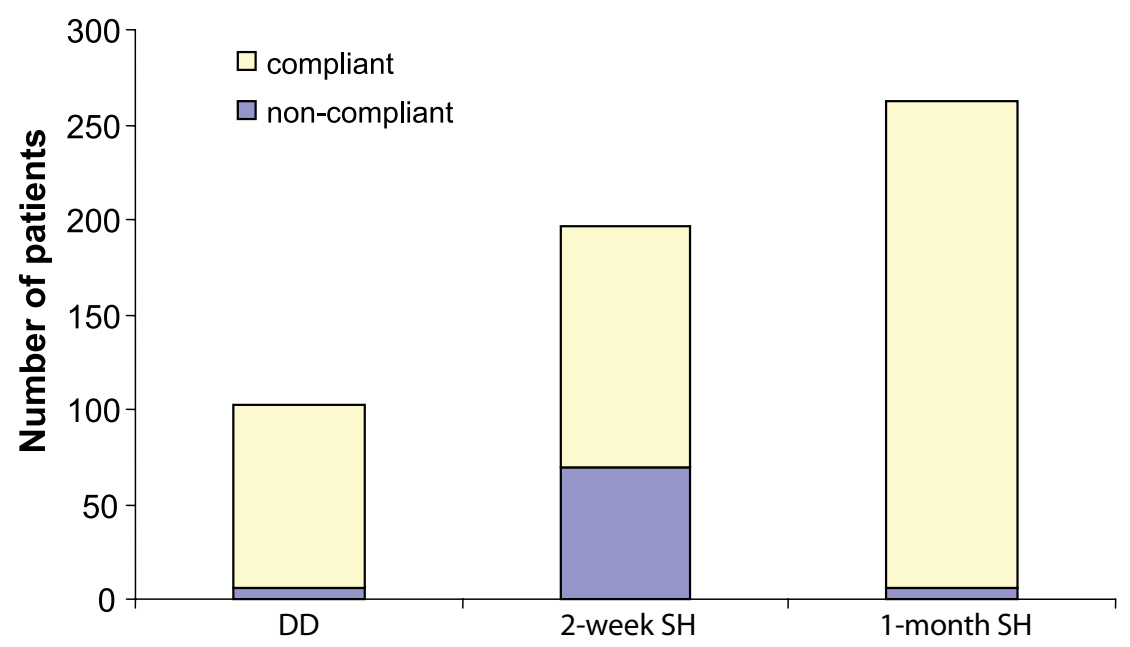

Figure 1: Optometrist compliance with manufacturer recommendations for $\mathrm{RF}$

\section{TABLE 1}

\section{DISTRIBUTION OF LENS BRANDS WORN}

\begin{tabular}{|c|c|c|c|}
\hline & Number & \% Lens Type & $\%$ Group \\
\hline \multicolumn{4}{|l|}{ 1-day lenses } \\
\hline 1 Day Acuvue (and Moist) & 27 & 26 & \multirow{10}{*}{18} \\
\hline 1 Day Acuvue for Astigmatism & 1 & 1 & \\
\hline Dailies (and Aqua, Aqua Plus) & 56 & 54 & \\
\hline Dailies Toric & 8 & 8 & \\
\hline Dailies Progressive & 3 & 3 & \\
\hline Proclear 1 Day & 3 & 3 & \\
\hline Freshlook 1-Day & 2 & 2 & \\
\hline Biomedics 1 Day Toric & 2 & 2 & \\
\hline Biomedics 1 Day & 1 & 1 & \\
\hline Soflens 1 Day & 1 & 1 & \\
\hline \multicolumn{4}{|l|}{ Two-week lenses } \\
\hline Acuvue Advance & 49 & 24 & \multirow{4}{*}{35} \\
\hline Acuvue Advance for Astigmatism & 38 & 19 & \\
\hline Acuvue Oasys & 100 & 49 & \\
\hline Acuvue Oasys for Astigmatism & 16 & 8 & \\
\hline \multicolumn{4}{|l|}{ 1-month lenses } \\
\hline Air Optix / Air Optix Aqua & 91 & 34 & \multirow{7}{*}{47} \\
\hline Air Optix Astigmatism & 14 & 5 & \\
\hline Night \& Day & 54 & 20 & \\
\hline Biofinity & 25 & 9 & \\
\hline PureVision & 28 & 10 & \\
\hline PureVision Toric & 34 & 13 & \\
\hline PureVision Multifocal & 25 & 9 & \\
\hline
\end{tabular}


TABLE 2

REPLACEMENT FREQUENCY RECOMMENDED BY OPTOMETRIST

\begin{tabular}{|c|c|c|c|c|c|c|c|c|c|}
\hline \multicolumn{10}{|c|}{ ORRF } \\
\hline Lens group & $1 \mathrm{D}$ & $2 \mathrm{D}$ & $3-6 D$ & $1 \mathrm{~W}$ & $2 W$ & $3 W$ & $1 \mathrm{M}$ & $2 \mathrm{M}$ & $\geq 3 M$ \\
\hline 1 day $(n=102)$ & $94.1 \%$ & 0 & 0 & 0 & $1.0 \%$ & 0 & $4.9 \%$ & 0 & 0 \\
\hline 2 weeks ( $n=197)$ & 0 & 0 & 0 & 0 & $65.0 \%$ & $1.5 \%$ & $32.0 \%$ & $1.5 \%$ & 0 \\
\hline 1 month $(n=262)$ & $0.4 \%$ & 0 & 0 & $0.4 \%$ & $6.5 \%$ & 0 & $90.5 \%$ & $0.4 \%$ & $1.9 \%$ \\
\hline
\end{tabular}

TABLE 3

REPLACEMENT FREQUENCY RECOMMENDED BY OPTOMETRIST, AS REPORTED BY PATIENT

\begin{tabular}{|l|c|c|c|c|c|c|c|c|c|c|}
\hline \multicolumn{10}{|c|}{ PRRF } \\
\hline Lens group & 1D & 2D & 3-6D & 1W & 2 W & 3 W & 1 M & 2 M & $\geq 3$ M & NR \\
\hline 1 day $(n=103)$ & $81.6 \%$ & $1.0 \%$ & $1.0 \%$ & 0 & $1.0 \%$ & 0 & $2.9 \%$ & 0 & 0 & $12.6 \%$ \\
\hline 2 weeks $(n=202)$ & $1.5 \%$ & 0 & $0.5 \%$ & $2.5 \%$ & $53.5 \%$ & $4.0 \%$ & $34.2 \%$ & $1.5 \%$ & $0.5 \%$ & $2.0 \%$ \\
\hline 1 month $(n=269)$ & $1.1 \%$ & 0 & 0 & $1.5 \%$ & $7.1 \%$ & $1.9 \%$ & $79.6 \%$ & $4.1 \%$ & $1.9 \%$ & $3.0 \%$ \\
\hline
\end{tabular}

\section{TABLE 4}

\section{REPLACEMENT FREQUENCY RELATIVE TO RECOMMENDED REPLACEMENT FREQUENCY}

\begin{tabular}{|l|c|c|c|c|}
\hline \multicolumn{4}{|c|}{ Replacement of contact lenses relative to what was recommended } \\
\hline Lens group & Always & Often & Sometimes & Rarely \\
\hline 1 day & $76 \%$ & $13 \%$ & $4 \%$ & $7 \%$ \\
\hline 2 weeks & $29 \%$ & $38 \%$ & $17 \%$ & $15 \%$ \\
\hline 1 month & $36 \%$ & $32 \%$ & $19 \%$ & $13 \%$ \\
\hline All lenses & $41 \%$ & $31 \%$ & $16 \%$ & $13 \%$ \\
\hline
\end{tabular}

A considerable percentage of ORRFs were longer than the MRRF for two-week lenses (35\%, 28 $42 \%)$. The non-compliance rates were lower for DD lenses $(6 \%, 2$ $-13 \%)$ and one-month lenses $(2 \%$, $1-5 \%)$. These results are summarized in Figure 1. Shorter ORRFs were recorded for $7 \%(5-11 \%)$ of one-month lens wearers. In most of those cases, the lens type worn was AIR OPTIX (also known as $\mathrm{O}_{2}$ OPTIX, CIBA Vision).
The ORRF non-compliance rate was higher for astigmatic lenses $(24 \%, 17-33 \%)$ than for spherical lenses $(11 \%, 8-15 \%)$.

\section{Data obtained from patients}

The distribution of responses for Recommended RF by the optometrist, as reported by the patient (PRRF), is listed in Table 3. The highlighted cells represent those PRRF that are compliant with the MRRF for the lens type. "NR" indicates that no recommendation was given.

Most two-week and one-month lens wearers were given a Recommended RF from their optometrist, but $13 \%(7.2-21.0 \%)$ of DD lens wearers reported not being given a recommendation for RF. In $78 \%$ of cases, the PRRF was in agreement with the ORRF. Fourteen percent were not in agreement, and $8 \%$ had one or both of the RFs missing or no recommendation was given. 
Patient compliance with recommended replacement frequency

Three questions were posed in an attempt to evaluate the actual compliance to lens replacement frequencies by patients. Table 4 lists the distribution of responses to the first question which asked patients how often they replace their contact lenses relative to what was recommended. A considerably higher percentage of DD lens wearers reported "always" replacing lenses at the recommended frequency compared to two-week and one-month lens wearers.

In the second question, patients were asked to give the primary reason they wore lenses longer than recommended. Overall, 35\% (30.9 $39.1 \%$ ) of patients who responded to the question reported that they never wore their lenses for longer than was recommended. This finding varied by group, with $73 \%(62.0$ $-81.1 \%$ ) of DD wearers, $22 \%$ (16.9 $-28.9 \%)$ of two-week wearers and $31 \%(25.5-37.2 \%)$ of one-month wearers responding that they never exceeded the Recommended RF. The most common reason given by DD wearers for wearing lenses longer than recommended was "to save money". For two-week and one-month wearers the most common reason was "forgetting which day to replace them".

Finally, patients were asked after how many days, and/or months they replaced their lenses. An actual RF of more than one day was considered to be non-compliant for

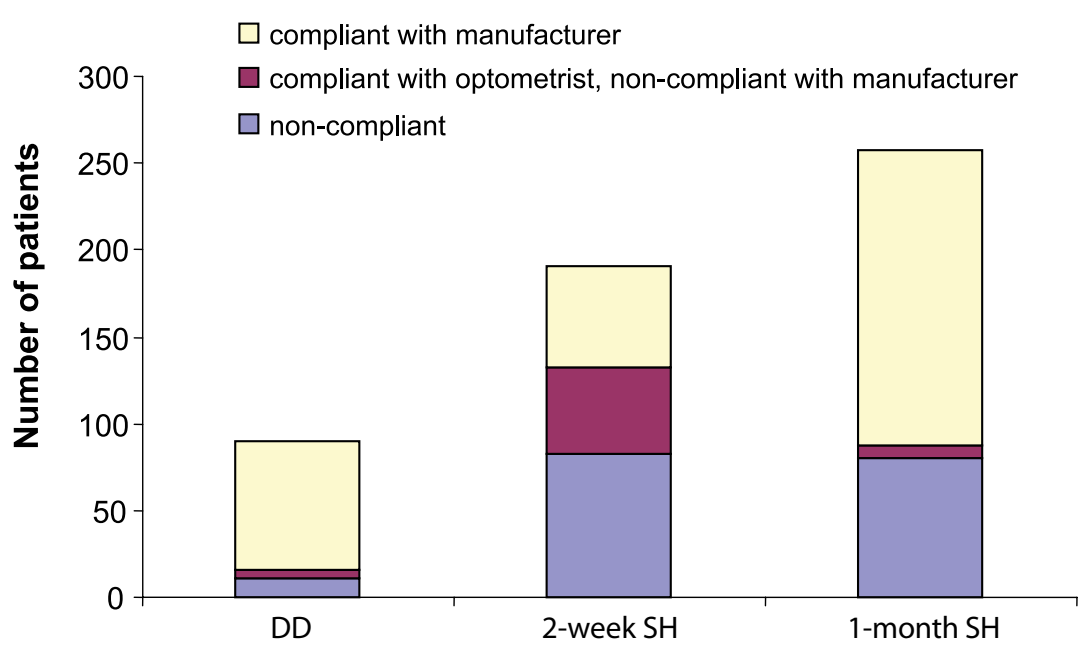

Figure 2: Patient compliance with optometrist and manufacturer recommendations for $R F$

DD lenses; more than 17 days was considered to be non-compliant for two-week lenses, and more than 31 days was considered to be noncompliant for one-month lenses. Overall, 44\% wore lenses longer than the MRRF. This varied by lens group, with the non-compliance rates being $18 \%(10.8-27.6 \%)$ for DD lenses, $69 \%(62.0-75.5 \%)$ for two-week lenses and 34\% (28.5 $40.4 \%$ ) for one-month lenses.

Since optometrists are not always compliant with the MRRF, particularly for two-week replacement lenses, some patients may appear to be non-compliant when in fact they are simply following the recommendation given by their optometrist. It may be more appropriate therefore to consider patients to be non-compliant only if they follow neither the MRRF nor the PRRF. Twenty-six percent of patients who were not compliant with the MRRF were nevertheless compliant with the recommendation they recalled being given by their optometrist. When these patients were included in the compliant group, the overall patient non-compliance rate was $32 \%(28.4-36.5 \%) ; 12 \%$ (6.6 21.2) for DD lens wearers, $43 \%$ $(36.4-50.8 \%)$ for two-week lens wearers and $31 \%(25.6-37.2 \%)$ for one-month lens wearers. The patient compliance results are summarized in Figure 2.

\section{Reminder systems}

Overall, $56 \%(50.4-58.7 \%)$ of patients thought a reminder system would help them to comply with the recommended replacement schedule. This was lower for DD wearers $(35 \%, 26.2-45.7 \%)$ than for two-week wearers $(61 \%$, $53.6-67.4 \%$ ) or one-month wearers $(57 \%, 50.8-63.1 \%)$. Patients were able to select one or more options which they thought would be useful from a list of suggested 
reminder systems. Seventeen percent of patients selected a paper calendar, $20 \%$ a cell phone or text message, $19 \%$ an email reminder, $29 \%$ a countdown display on the lens case, and $24 \%$ reported that establishing a particular day each week or month would be useful.
Results by patient

\section{compliance group}

Some data for compliant and noncompliant patients were analyzed further to investigate the possible associations with, and reasons for, non-compliance.

\section{Demographics and lens wearing patterns}

The mean age of non-compliant patients was $32.7 \quad(30.9-34.5)$ \pm 11.9 years, which was similar to the mean age of compliant patients 34.1 (32.7-35.4) \pm 13.1 years. Thirty percent of females and $37 \%$ of males were non-compliant. The average total years of lens wear was quite high for both compliant and non-compliant patients (11.7 and 13.0 years respectively). A higher percentage of patients wearing lenses to correct astigmatism were non-compliant $(40 \%, 31.4-50.0 \%)$

\section{TABLE 5}

\section{AGREEMENT WITH STATEMENTS ACCORDING TO COMPLIANCE GROUP}

\begin{tabular}{|c|c|c|c|}
\hline \multirow[b]{2}{*}{ Statement } & \multicolumn{3}{|c|}{ Response: Agree or Strongly Agree } \\
\hline & Compliant & Non-compliant & $\begin{array}{l}\text { Difference } \\
\text { Compliant - non-compliant } \\
(95 \% \mathrm{Cl})\end{array}$ \\
\hline $\begin{array}{l}\text { If my eye care professional tells me to do something } \\
\text { to care for my contact lenses, I do it. }\end{array}$ & $94 \%$ & $77 \%$ & $\begin{array}{c}17 \% \\
(10.8 \text { to } 24.9 \%)\end{array}$ \\
\hline $\begin{array}{l}\text { My eye care professional clearly explained the } \\
\text { replacement schedule for my current lenses. }\end{array}$ & $93 \%$ & $84 \%$ & $\begin{array}{c}9 \% \\
(3.2 \text { to } 16.1 \%)\end{array}$ \\
\hline $\begin{array}{l}\text { I follow the recommended replacement schedule } \\
\text { because I have complete confidence in my eye care } \\
\text { professional. }\end{array}$ & $87 \%$ & $51 \%$ & $\begin{array}{c}36 \% \\
(27.7 \text { to } 44.7 \%)\end{array}$ \\
\hline $\begin{array}{l}\text { I definitely don't dare miss replacing my contacts on } \\
\text { the regular schedule. }\end{array}$ & $57 \%$ & $16 \%$ & $\begin{array}{c}41 \% \\
(32.8 \text { to } 48.4 \%)\end{array}$ \\
\hline $\begin{array}{l}\text { I follow the recommended replacement schedule } \\
\text { because it leads to fewer problems with my eyes. }\end{array}$ & $78 \%$ & $38 \%$ & $\begin{array}{c}41 \% \\
(31.7 \text { to } 49.0 \%)\end{array}$ \\
\hline $\begin{array}{l}\text { Uncomfortable lenses make me more likely to follow } \\
\text { the recommended replacement schedule. }\end{array}$ & $81 \%$ & $79 \%$ & $\begin{array}{c}2 \% \\
(-5.1 \text { to } 10.2 \%)\end{array}$ \\
\hline $\begin{array}{l}\text { The quality of my vision tells me it is time to replace } \\
\text { my contact lenses. }\end{array}$ & $56 \%$ & $72 \%$ & $\begin{array}{c}-15 \% \\
(-23.6 \text { to }-6.2 \%)\end{array}$ \\
\hline $\begin{array}{l}\text { If I don't replace my lenses on the recommended } \\
\text { schedule, I have problems with my vision. }\end{array}$ & $42 \%$ & $31 \%$ & $\begin{array}{c}11 \% \\
(2.4 \text { to } 19.6 \%)\end{array}$ \\
\hline $\begin{array}{l}\text { The risk of a serious eye infection would make } \\
\text { me more likely to follow the recommended } \\
\text { replacement schedule. }\end{array}$ & $87 \%$ & $83 \%$ & $\begin{array}{c}4 \% \\
(-2.7 \text { to } 11.1 \%)\end{array}$ \\
\hline $\begin{array}{l}\text { I use a calendar or other system to remind me to } \\
\text { replace my lenses on the schedule recommended } \\
\text { by my eye care professional. }\end{array}$ & $45 \%$ & $21 \%$ & $\begin{array}{c}25 \% \\
(15.9 \text { to } 32.3 \%)\end{array}$ \\
\hline
\end{tabular}


compared to patients wearing spherical corrections $(30 \%, 26.2-$ $35.2 \%)$.

\section{Patient opinions}

A larger proportion of compliant patients $(87 \%)$ than non-compliant patients $(58 \%)$ thought it was "extremely important" or "important" to replace their contact lenses on schedule.

A series of questions regarding interactions between the patient and his/her optometrist were included in the survey. The majority of both compliant and non-compliant patients felt that it was either "important" or "very important" for their optometrist to explain the risks associated with non-compliance $(76 \%)$, but a higher proportion of compliant patients $(70 \%)$ than non-compliant patients $(55 \%)$ felt it was important for the optometrist to explain the replacement schedule in detail.

Patients were asked to indicate their agreement with ten statements relating to their eye care professional and contact lens wear. The differences in the percentages of compliant and non-compliant patients responding that they "agreed" or "strongly agreed" with the statements are shown in Table 5. For many of the statements, a higher percentage of the compliant group responded either "agree" or "strongly agree".

\section{Lens care practices}

Thirty-four percent of patients wearing two-week or one-month lenses were unsure of the name of the care system they were using. This was similar for compliant (35\%) and non-compliant (32\%) patients. A high percentage of both compliant and non-compliant patients thought it was "important" or "extremely important" to clean their lenses every day $(90 \%$ and $86 \%$ respectively). Most patients reported replacing their lens case at least once every six months. The percentages of compliant and noncompliant patients reporting that they replaced their lens case only every year or "never" were $18 \%$ and $22 \%$ respectively.

\section{Discussion}

The main aim of this study was to investigate optometrist and patient compliance with recommended replacement schedules for DD contact lenses, and two-week and one-month $\mathrm{SH}$ contact lenses in Canada. The survey was conducted such that the patient's responses were not known to the optometrist, and the optometrist's identity was not known to the study coordinators. It was hoped that this level of anonymity would encourage honest responses to the survey questions.

The study cohort consisted of Canadian patients and the results showed them to be representative of the current contact lens wearing population in the Canada in terms of gender and age. ${ }^{1} \mathrm{Al}-$ though optometrists from nine provinces agreed to participate, the distribution of the returned surveys by province was not known. It is possible that there are regional differences in the practices of optometry within Canada that are not reflected in these survey results.

Forty-seven percent of respondents wore one-month $\mathrm{SH}$ lenses, $35 \%$ wore two-week SH lenses, and $18 \%$ wore DD lenses. The percentage of patients wearing lenses fewer than seven days per week was highest in the DD lens group. Clearly DD lenses are a convenient choice for patients who do not wish to wear lenses every day.

The results of the current study show that optometrists recommend longer intervals than the MRRF for an estimated $35 \%$ of their twoweek SH replacement patients but are compliant with recommendations for most of their DD and one-month SH patients. According to patients, no recommendation was given by their optometrist for about $13 \%$ of DD wearers but this does not necessarily mean that these patients were not given instructions to discard the lenses after each wearing day. The instructions might simply not have been interpreted as being recommendations for replacement frequency, especially if the lenses were not worn every day. In $14 \%$ of cases the Recommended RF reported by the patient was not in agreement with the Recommended RF reported by the optometrist. These disparities may have occurred for a variety of reasons. Optometrists may have felt obliged to record the correct MRRF on the envelope, even though the study was conducted anonymously, rather than the RF that they had actually recommended to their patients. Patients may not have 
accurately remembered what recommendation they had been given by their optometrist. It is also possible that some of these patients were actually wearing a different lens type from that recorded by the optometrist; there was a discrepancy between the optometrist's recorded lens brand and the patient's recorded lens brand in $5 \%$ of cases, and a further $29 \%$ of patients were unsure of their lens brand.

Many patients reported actual RFs which did not comply with the manufacturer's recommendation, or the recommendation they recalled being given by their optometrist. The non-compliance rate was lowest for DD lens wearers $(12 \%)$. Two-week lens wearers had the highest non-compliance rate (43\%) followed by one-month wearers $(31 \%)$. Similar results, within the margin of error of this study, were obtained in a previous study evaluating compliance with replacement of conventional lens materials in the US and Canada. ${ }^{11}$

When optometrist and patient non-compliance is combined, the result is that about $44 \%$ of patients wearing DD lenses or two-week or one-month $\mathrm{SH}$ lenses, are not replacing their lenses according to the manufacturer's recommendations.

The relatively low proportion of DD patients wearing their lenses for longer than a single one day period may not be inconsequential considering that cases of Acanthamoeba keratitis have been reported in patients re-using lenses designed for daily disposal. ${ }^{15,16}$ On the other hand, the consequences of wearing a
SH lens for longer than the MRRF are not known at this time since there have been no studies to-date specifically investigating this issue. A study conducted in Singapore reported that using lenses past their recommended replacement date increased the likelihood of developing Fusarium keratitis; ${ }^{17}$ however, that study included many lens types and the risk may vary with the lens material.

Seventy-eight percent of patients said that they thought replacing their lenses on schedule was "extremely important" or "important". It is perhaps not surprising that non-compliant patients were less likely than compliant patients to have the perception that replacing lenses on schedule is important ( $58 \%$ versus $87 \%$ ). Greater than half the patients wearing two-week $\mathrm{SH}$ and one-month $\mathrm{SH}$ lenses felt that a lens replacement reminder system would be useful. Interestingly $45 \%$ of patients who were compliant with scheduled lens replacement reported using a calendar or other system to remind them to replace their lenses as compared with only $21 \%$ of non-compliant patients.

The interaction between a patient and their optometrist may be important for establishing compliance considering that the majority of patients felt that it was either "important" or "very important" for their optometrist to explain the risks associated with noncompliance. Some differences between compliant and non-compliant patients were apparent from the responses to some of the statements incorporated in the survey. A considerably higher proportion of compliant patients reported following their recommended replacement schedule because they have complete confidence in their eye care professional $(87 \%$ versus $51 \%)$ and that they follow the recommended replacement schedule because it leads to fewer problems with their eyes $(78 \%$ versus $38 \%$ ). This would seem to indicate that some patients are compliant because they are not willing to assume the perceived risks of non-compliance, and that they trust the information they have received from their optometrist concerning those risks. In contrast, a higher proportion of non-compliant patients agreed with the statement: "the quality of my vision tells me it is time to replace my contact lenses" ( $72 \%$ versus $56 \%$ ). Some patients may be non-compliant because they place less importance on the potential risks of non-compliance and instead replace their lenses based on symptoms they experience.

In other studies on compliance with contact lens wear and care, differences between compliant and non-compliant patients were reported, but the emphasis was on compliance as it relates to lens care, not replacement frequency. ${ }^{18,19}$ Compliance is a complex issue and attempts to identify predictors of compliance have generally not been successful. ${ }^{20}$

In the current study, there was no strong evidence that there is an age or gender difference between compliant and non-compliant patients in relation to lens RF. Those patients requiring a correction for 
astigmatism were less compliant with replacement recommendations than patients wearing a spherical correction. The higher cost of toric contact lenses may compel some patients to extend the replacement interval for their lenses in order to save money. Lens care behaviors were investigated for two-week SH and one-month $\mathrm{SH}$ lens wearers. Non-compliance with lens RF did not seem to be strongly related to non-compliant attitudes towards lens care procedures. It is reasonable to hypothesize that patients feel that non-compliance with lens hygiene procedures carries a higher risk than non-compliance with lens RF. Additional data regarding the actual lens care practices of patients would be required to test this hypothesis.

\section{Conclusion}

This study has investigated patient and optometrist behaviors with respect to RF for commonly prescribed contact lenses in Canada. Optometrists generally Recommended RFs consistent with manufacturers' recommendations for DD and one-month SH lenses but often recommended longer intervals for two-week SH lenses. Patients were most compliant when wearing DD lenses and least compliant when wearing two-week SH lenses. Greater than half of those wearing twoweek $\mathrm{SH}$ or one-month $\mathrm{SH}$, and not replacing lenses when recommended, reported that this was because they forgot which day to replace their lenses. For those patients, initiating a reminder system may aid compliance with RF. Over half of
DD lens wearers who did not replace lenses when recommended, reported that this was because they wanted to save money. Communication between the patient and optometrists concerning the risks of non-compliance might be helpful in these cases.

\section{Acknowledgements}

Funding for this work was received from Ciba Vision Canada. We thank Dr. Etty Bitton, Associate Professor of Optometry, Université de Montréal and the Canadian Association of Optometry for their assistance with the study.

\section{Corresponding author:}

Dr. Doris Richter

Centre for Contact Lens Research

School of Optometry

University of Waterloo

Waterloo, Ontario

N2L 3 G1 Canada

$T-519888-4742$

F- 519 884-8769

dbrichte@uwaterloo.ca

\section{References}

1. Morgan PB, Woods C, Tranoudis I et al.: International contact lens prescribing in 2008. Contact Lens Spectrum 2009; 24;2: 28-32.

2. Poggio EC, Abelson MB: Complications and symptoms with disposable daily wear contact lenses and conventional soft daily wear contact lenses. CLAO J 1993; 19;2: 95-102.

3. Hamano $\mathrm{H}$, Watanabe $\mathrm{K}$, Hamano $\mathrm{T}$ et al: A study of the complications induced by conventional and disposable contact lenses. CLAO J 1994; 20 (2): 103-108

4. Pritchard N, Fonn D, Weed K: Ocular and subjective responses to frequent replacement of daily wear soft contact lenses. CLAO J 1996; 22;1: 53-59.

5. Solomon OD, Freeman MI,Boshnick EL et al.: A 3-year prospective study of the clinical performance of daily disposable contact lenses compared with frequent replacement and conventional daily wear contact lenses. CLAO J 1996; 22;4: 250-257.

6. Porazinski AD, Donshik PC: Giant papillary conjunctivitis in frequent replacement contact lens wearers: a retrospective study. CLAO J 1999; 25 (3): 142-147

7. Suchecki JK, Ehlers WH, Donshik PC et al.: A comparison of contact lensrelated complications in various daily wear modalities. CLAO J 2000; 26;4: 204-213.

8. Brennan NA, Coles M-LC: Deposits and symptomatology with soft contact lens wear. Int Contact Lens Clin 2000; 27 (3): 75-100

9. Smith SK: Patient noncompliance with wearing and replacement schedules of disposable contact lenses. J Am Optom Assoc 1996; 67;3: 160-164.

10. Coopersmith L, Weinstock FJ: Current recommendations and practice regarding soft lens replacement and disinfection. CLAO J 1997; 23;3: 172-176.

11. Jones L, Dumbleton K, Fonn D et al.: Comfort and compliance with frequent replacement soft contact lenses. Optom Vis Sci 2002; 79;12s: 259.

12. Morgan P: Contact lens compliance and reducing the risk of keratitis. Optician 2007; 234;6109: 20-25.

13. Morgan PB, Woods C, et al.: International contact lens prescribing in 2007. Contact Lens Spectrum 2008; 23;1: 36-41.

14. Dumbleton K, Woods C, Jones L et al: Patient and practitioner compliance with silicone hydrogel and daily disposable lens replacement in the United States of America. Eye \& Contact Lens 2009; 35;4: 164-171.

15. S.A. Woodruff and J.K.G. Dart: Acanthamoeba keratitis occurring with daily disposable contact lens wear, $\mathrm{Br} \mathrm{J}$ Ophthalmol 1999; 83: 1088-1089.

16. Niyadurupola N, Illingworth CD: Acanthamoeba keratitis associated with misuse of daily disposable contact lenses. Cont Lens Anterior Eye 2006; 269-271.

17. Saw SM, Ooi PL, Tan DT et al.: Risk factors for contact lens-related fusarium keratitis: a case-control study in Singapore. Arch Ophthalmol 2007; 125;5: 611-617.

18. Radford C, Woodward EG and Stapleton F. Contact lens hygiene compliance in a university population. J BCLA, 1993; 16(3) 105-111.

19. Claydon BE, Efron N, Woods C. A prospective study of non-compliance in contact lens wear. J. Br. Contact Lens Assoc 1996; 19:133-140.

20. Efron N: The truth about compliance. Contact Lens And Anterior Eye 1997; 20;3: 79-86. 